\title{
EL KITĀB AL-ANWĀR Y LA CIRCULACIÓN DE LIBROS EN AL-ANDALUS*
}

\author{
Maribel Fierro**
}

Debemos a María Luisa Lugo Acevedo un excelente estudio sobre una obra, El libro de las luces ${ }^{1}$, muy popular entre mudéjares y moriscos. Tanto la obra como el estudio arrojan nueva y valiosa luz sobre la historia cultural de al-Andalus. Como no soy especialista en la historia de los mudéjares y moriscos, pero sí me intereso desde hace mucho tiempo por la actividad y producción intelectuales en al-Andalus, se me perdonará que -además de felicitar a la autora por los frutos alcanzados en su investigación- me extienda en la importancia de esa investigación para los 'andalusistas'.

Los investigadores que se han ocupado de las bibliotecas de mudéjares y moriscos y, en general, de los libros que poseían, leían y estudiaban han podido documentar que una gran parte de ellos había estado circulando previamente en la Península Ibérica. Basta pensar en obras como la Risāla de Ibn Abī Zayd al-Qayrawānī, el Tafrī̄ , de Ibn al-Ŷallāb, el Tanbīh de al-Samarqandī o el Tahdi $\bar{\imath} b$ al-Barāâdi $\bar{i}_{\overline{1}}$, por citar unas pocas. En ocasiones, sin embargo, resulta difícil encontrar una correspondencia entre una parte de la literatura que circulaba entre los mudéjares y moriscos y aquella de la que nos informan las fuentes andalusíes, fuentes entre las que sobresalen - por el volumen de información

* Este trabajo recoge una parte de mi comunicación titulada «De nuevo sobre los libros de los moriscos» que fue leída en el Congreso Internacional La identidad islámica de los moriscos. Homenaje a Mikel de Epalza, celebrado en la Universidad de Alicante los días 23-26 de noviembre de 2009. Quiero agradecer a Luis F. Bernabé Pons su amable invitación a participar en dicho congreso. Por razones que no vienen al caso, no pude entregar este trabajo para el volumen en el que se publica dicho Homenaje, pero me alegra que salga en una revista tan vinculada a Míkel de Epalza, a quien tengo que agradecer que, siendo una doctora reciente, contase conmigo para un Curso de Verano de la Universidad Complutense (1991), gracias al cual aprendí cómo no debía dar una conferencia.

** CCHS-CSIC.

1. M.L. Lugo Acevedo (ed.), El libro de las luces. Leyenda aljamiada sobre la genealogía de Mahoma. Estudio y edición crítica, Madrid, 2008. 
que brindan- los diccionarios biográficos y bibliográficos que se ocupan del mundo de los ulemas, es decir, de los especialistas en el saber normativo islámico. En estos casos, la información procedente de las épocas mudéjar y morisca nos obliga a plantearnos el hecho de que determinadas obras no documentadas en fuentes andalusíes debieron, sin embargo, de circular en al-Andalus y, por tanto, nos obliga a enfrentarnos a las limitaciones de las fuentes a nuestra disposición y a reconocer que nos brindan una visión parcial -sin que podamos precisar hasta qué punto- de la historia intelectual andalusí.

El ejemplo más revelador de esta disparidad tiene que ver con la obra -El Libro de las luces- mencionada anteriormente. El Libro de las luces ha sido editado por María Luisa Lugo Acevedo a partir de la versión aljamiada recogida en el ms. de la Biblioteca de la Real Academia de la Historia T-17, pero utilizando también los mss. de la Biblioteca Nacional de Madrid 4955, BRAH T-18, Biblioteca del Palacio Real 3225 y el ms. de Urrea de Jalón. En esta obra se narra la genealogía del profeta Muhammad, su nacimiento y su infancia, empezando con la creación de Adán, cuando Dios colocó una luz milagrosa en la frente de Adán que se fue transmitiendo hasta llegar al Profeta. La transmisión de esa luz no estaba limitada a los antecesores varones de Muhammad, pues pasaba también a las mujeres. Entre ellas la recibió la madre del Profeta, Amīna, perdiéndola una vez que hubo acido su hijo, ya que pasó a él.

El Libro de las luces no es una obra compuesta en ambientes mudéjares o moriscos, sino que depende de un original escrito en árabe, el Kitāb al-anwā̄r, obra que se atribuye a un personaje generalmente conocido como al-Bakrī, del que apenas se tienen datos biográficos. Se le suele identificar con un Abñ 1-Hasan Aḥmad b. 'Abd Allāh al-Bașrī cuya cronología no está clara. Su biografía aparece por vez primera en una obra de al-Dahabī (m. 748/1348), quien descalifica a al-Bakrī como embustero y falso, al tiempo que asegura que se trata del autor de obras que vendían los libreros, indicando con ello que tenían gran circulación y aceptación. Tal y como explica Franz Rosenthal en la entrada que le dedica en la Encyclopaedia of Islam (segunda edición), dado que un ms. del Kitāb al-anwwār (Vaticano Borg. 125) está fechado en 694/1295 y dado que en esa obra se cita a autores que vivieron al final del s. VII / XIII', habría que situar a al-Bakrī en la segunda mitad del s. VII/XIII. Sin embargo, Boaz Shoshan ha señalado que se podría proponer una fecha mucho más temprana, el s. III/ IX ${ }^{3}$. Se puede ahora adelantar la composición de la obra gracias a un estudio reciente de Óscar de la Cruz Palma ${ }^{4}$, en el que se demuestra que el Kitāb al-anwār (en una de las ver-

2. F. Rosenthal, para esta última información, remite a W. AHLWARDT, Verzeichniss der arabischen Handschriften der Koniglichen Bibliothek zu Berlin, 10 vols., Berlín, 1887-1890, nº 9624, sin plantearse la posibilidad de que esas citas puedan ser interpolaciones.

3. Boaz SHoshan, Popular culture in medieval Cairo, Cambridge, 1993, pp. 35-36.

4. Ó. DE la CRUz PALMA, «Notas a la lectura del Liber de generatione Mahumet (trad. de Hermán de Carintia, 1142-1143)», en curso de publicación en las Actas del V Congreso Internacional de 
siones en las que debió de circular) corresponde a la obra traducida al latín por Hermán de Carintia entre 1142-1143 con el título Liber de generatione Mahumet. Esta traducción prueba que una obra árabe de contenido muy similar al de la versión aljamiada (en sus distintos 'testimonios' en afortunada expresión de Lugo Acevedo) circulaba en la Península Ibérica en el s. VI/XII, antes pues de lo indicado por el ms. Vaticano Borg. 125 fechado en Denia en $1295^{5}$. Como todavía carecemos de un estudio a fondo de los manuscritos que se conservan del original árabe, seguimos sin poder adelantar de manera segura la composición de la obra hasta ese siglo III / IX mencionado por Shoshan.

María Luisa Lugo Acevedo ha consultado dos de esos manuscritos árabes, el ya mencionado, Vaticano Borg. 125, y uno en la Biblioteca Nacional de Túnez. No ha tenido acceso -a lo que parece- a ninguna de las ediciones del Kitāb alanwār de las que da cuenta B. Shoshan ${ }^{6}$. Son ediciones sin aparato crítico, a lo que se añade-ya se ha dicho- la ausencia de un estudio en profundidad en el que se analicen los manuscritos que de la obra se conservan y que permita, por tanto, precisar el área de su difusión. Esas ediciones modernas, en cualquier caso, siguen dando fe de la extraordinaria difusión y popularidad de esta obra en el presente, popularidad que tiene sin duda que ver con el énfasis en los aspectos más carismáticos de la figura del Profeta.

Volviendo al aspecto indicado al principio -el de la correspondencia entre la literatura de mudéjares y moriscos y la literatura andalusí-, mientras que tenemos constancia de que el Kitāb al-anwār circulaba en la Península Ibérica al menos desde el siglo VI/XII (cuando fue traducido al latín) y de que era copiado bajo dominio cristiano en Denia en 1295 así como vertido al romance, ninguna fuente, en cambio, cita su circulación en árabe entre la población andalusí. Puedo asegurar -a partir de la información recogida en la base de datos Historia de los Autores y Transmisores de al-Andalus (HATA) - que la obra árabe de alBakrī no se menciona en ninguno de los diccionarios biográficos ni en ninguno de los repertorios bibliográficos andalusíes que se conservan. En otras palabras, si no dispusiésemos de la información que nos brindan la traducción latina de Hermán de Carintia y los libros de los mudéjares y moriscos, podríamos concluir que esta obra oriental nunca llegó a la Península Ibérica, lo cual a su vez podría llevar a determinadas interpretaciones sobre la historia cultural e intelectual de al-Andalus, sobre todo en lo que respecta a la relación entre

Latín Medieval Hispánico, celebrado en la UAB-UB-Montserrat entre los días 7-11 de septiembre de 2009 (en prensa para la SISMEL, previsiblemente en 2011). Agradezco a su autor su amabilidad al dejarme consultar el original antes de su publicación.

5. Denia estaba entonces bajo dominio de la Corona de Aragón (Jaime I la conquistó en 1244), lo cual indica que ese manuscrito debió de ser copiado por un musulmán que tendría el estatuto de mudéjar.

6. Debo a mi colega Avraham Hakim poder disponer de una copia de la edición de Beirut: alMaktaba al-šacbiyya, 1379/1959.

7. M. Fierro, «Manuscritos en al-Andalus. El proyecto H.A.T.A. (Historia de los Autores y Transmisores Andalusies)», Al-Qanțara, XIX, 1998, pp. 473-502. 
lo local y lo global. Recordemos que el Kitāb al-anwār circuló ampliamente, por ejemplo, en el Egipto mameluco.

¿Cómo podemos explicar el silencio de las fuentes andalusíes respecto al Kitāb al-anwār? ¿Hemos de pensar que los andalusíes del s. VI/XII -incluso los de los siglos anteriores si es que el Kitāb al-anwār fue compuesto en el s. III/IX-no le prestaron demasiada atención? Pero de ser así, ¿cómo es que fue seleccionado para su traducción al latín? Es de suponer, en efecto, que esa selección debió de estar motivada por la representatividad de la obra, es decir, por considerarse que se trataba de una obra que reflejaba bien las creencias de los musulmanes sobre su Profeta. ¿O es que tal vez el Kitāb al-anwār fue prohibido o al menos censurado, circulando de manera restringida o clandestina? ¿O simplemente circulaba fuera de los circuitos de los que nos informan las fuentes escritas a nuestra disposición? Después de todo, conocemos qué libros relativos a la religión islámica circulaban en al-Andalus a través de fuentes escritas por los especialistas en el saber religioso (ulemas), quienes tienden naturalmente a dejar constancia de aquellos libros que eran considerados aceptables desde el punto de vista normativo, mientras que procurarían silenciar aquellos que no lo eran. Tenemos que admitir que es muy poco lo que sabemos sobre aquellos libros que podían ser vistos con suspicacia, reprobados y / o prohibidos por los ulemas. Pues bien, la crítica vertida por al-Dahabī con respecto a al-Bakrī y su obra es ya un indicio claro de que dentro del grupo de los ulemas no debió de circular el Kitäb al-anwār o que, si lo hizo, lo fue o bien de manera vergonzante o bien para someterlo a crítica y refutación o bien en contextos muy determinados que hay que poder explicar.

Los investigadores occidentales -por regla general- han tendido y seguimos tendiendo a prestar atención a aquellos aspectos de la cultura escrita islámica que tienen que ver con el islam normativo, el propugnado por los ulemas como representativo de la ortodoxia, fundamentalmente porque es aquél sobre el que disponemos de un mayor número de fuentes para la época premoderna. Con la excepción de obras como Las mil y una noches -cuya traducción tuvo una gran influencia en Occidente y que hace de esa obra una excepción que tiene que ver más con el interés por nuestra propia cultura que no por la cultura popular islámica-, son pocos los investigadores que se ocupan o se han ocupado de esa otra escritura, la que parece existir en los márgenes de la 'oficial'. Y digo que esa otra escritura -la no normativa- parece existir en los márgenes porque ahí es donde la quieren arrinconar fuentes como los diccionarios biográficos de ulemas o los repertorios bibliográficos, mientras que de hecho fue aquella de la que participaban la mayoría de los musulmanes, incluyendo también a algunos (¿muchos?) ulemas, tal y como han puesto de relieve investigadores como B. Shoshan, J. Berkey y N. Hanna al estudiar la vida religiosa e intelectual egipcia en distintas épocas ${ }^{8}$.

8. Boaz SHOSHAN, op. cit.; J. BERKEY, Popular preaching and religious authority in the Medieval Islamic Near East, Seattle, WA, 2001; N. HANNA, In praise of books: a cultural history of Cairo's middle class, Syracuse, NY, 2003. 
Ahora bien, aun aceptando con estos investigadores que de hecho no había solución de continuidad entre la alta y la baja cultura, también es cierto que algunos ulemas -en tanto que representantes de la alta cultura- hacían grandes esfuerzos por establecer líneas diferenciadoras claras entre una y otra y por poner freno a la difusión de aquellos libros que desaprobaban. Como bien señala Lugo Acevedo' ${ }^{9}$ cada vez es más insostenible para los investigadores una diferenciación estricta entre historia y ficción, pero sigue siendo también indiscutible que una parte del esfuerzo de los ulemas de las sociedades islámicas premodernas consistió precisamente en establecer dicha diferenciación. De ahí las acusaciones formuladas por al-Dahabī y otros contra al-Bakrī acusándolo de fabulador y mentiroso. Nos hallamos ante procesos de construcción de la ortodoxia que implican -naturalmente- la marginación más o menos duradera de determinadas tendencias o doctrinas, procesos sobre los que hay un interés creciente y sobre los que ya contamos con buenos estudios, como el de Houari Touati para el siglo XVIII en el Norte de África ${ }^{10}$ o como el de Daniella Talmon Heller para la Siria de época ayyubí ${ }^{11}$. Nos encontramos ahora mismo en un momento de inflexión, en el sentido de que está creciendo el número de investigadores que centran su interés en el tipo de literatura que podríamos llamar no normativa (denominación que incluye la 'popular', pero no se limita a ésta), lo cual va a suponer una renovación de nuestro conocimiento de las sociedades islámicas premodernas. Por ejemplo, Marina Pyrovolaki, en una tesis titulada Futuh al-Sham and other futuh texts: a study of the perception of marginal conquest narratives in Arabic in medieval and modern times, leída en 2009 en la Universidad de Oxford, se ha concentrado en el estudio de las obras de maḡāzi de carácter popular que alcanzaron una gran difusión en el mundo islámico a partir de las Cruzadas, señalando que en momentos de antagonismo o de peligro para un determinado orden religioso y político suele producirse un renovado entusiasmo a la hora de escribir y reescribir la historia de sus comienzos, actividades éstas que sirven para dar legitimidad a ese orden, mantener sus ideales y fortalecer el sentimiento de identidad comunitaria. Esto lo saben bien quienes estudian la literatura de mudéjares y moriscos. En efecto, en dicha literatura abundan también los textos sobre las campañas militares de las primeras generaciones de musulmanes que posibilitaron la expansión del islam y la constitución del imperio islámico. En esos textos destacan sobre todo las figuras del segundo y el cuarto califa, 'Umar b. al-Jațtāb y c'Alī b. Abī Ṭālib, que son también -de los cuatro califas ortodoxos- los dos que fueron representados de manera más reiterada y llamativa como seres excepcionales. El primero, 'Umar, ha pasado a ser célebre por su imposición severa -con frecuente recurso al casti-

9. M.L. Lugo Acevedo (ed.), op. cit., p. 70.

10. H. TOUATI, Entre Dieu et les hommes : lettrés, saints et sorciers au Maghreb (XVII siècle), París, 1994.

11. D. TALMON-Heller, Islamic piety in medieval Syria: mosques, cemeteries and sermons under the Zangids and Ayyubids (1146-1260), Leiden, 2007. 
go corporal- de las normas islámicas ${ }^{12}$. El segundo, ${ }^{\mathrm{c}} \mathrm{Al} \overline{1}$, es conocido por su valentía en el combate y por la atribución de empresas fantásticas en las que a menudo lucha contra genios y demonios, tal y como ha quedado reflejado en el Libro de las batallas ${ }^{13}$, dentro de una tradición literaria no exclusiva del mundo šĩí sobre la que cada vez disponemos de más estudios ${ }^{14}$.

En el terreno de este último tipo de literatura, el de las magāzī o campañas militares de la primera época legendarias, y por lo que se refiere a al-Andalus, se puede rastrear una tradición local que va desde por lo menos la primera mitad del s. V / XI hasta la época de los moriscos. Me refiero a la versión de los Futūh al-Šàm transmitida por Abñ 'Umar al-Ṭalamankī (m. 429/1037) y de la que se conservan algunos manuscritos, entre ellos uno en la Real Academia de la Historia, Madrid, Col. Gayangos, XVIII ${ }^{15}$. Creo que valdría la pena investigar hasta qué punto esta fuente -que podríamos llamar 'andalusí', no porque se originase en al-Andalus sino por estar atestiguada su transmisión en la Península Ibérica- está detrás de los materiales de maḡāzi que circulaban entre los moriscos. Nos hallamos ante un caso parecido al del Kitāb al-anwāar, dado que la transmisión de los Futūh al-Šām por parte de al-Ṭalamankī no es registrada por la literatura bio-bibliográfica, teniendo noticia de ella únicamente por la existencia de manuscritos que la documentan. Y como en el caso de alBakrī -aunque con diferencias- la fiabilidad y la ortodoxia de al-Țalamankī también fueron puestas en duda, en el caso del andalusí por sus tendencias sufíes y por su activismo político-religioso, caracterizado -al parecer- por su inclinación hacia un liderazgo carismático de la comunidad musulmana, lo cual le llevó a ser procesado en Zaragoza ${ }^{16}$.

Con la figura de al-Ṭalamankī y sus tendencias sufíes volvamos ahora a la cuestión de la circulación del Kitāb al-anwār en la Península Ibérica. María Luisa

12. A. HAKIM, «Conflicting images of lawgivers: the caliph and the Prophet sunnat 'Umar and sunnat Muhammad», en H. BERG (ed.), Method and theory in the study of Islamic origins, Leiden-Boston, 2003, pp. 159-177; idem, «'Umar b. al-Jațțāb, calife par la grâce de Dieu», Arabica, LIV /3, 2007, pp. 317-361 y «'Umar b. al-Khaț̣āb a fighter against Satan», Jerusalem Studies in Arabic and Islam, 31, 2006, pp. 34-57; F. GuILlén Robles, Leyendas moriscas, 3 vols., Madrid,1886; edición facsímil con estudio preliminar de Ma Paz Torres, Granada, 1994, III, pp. 63 197; N. MARTínez DE CASTILlA, «La tradición literaria del castigo de Omar a su hijo», en A. TEMIMI (ed.), Hommage à l'École d'Oviedo d'Études Aljamiado, Zaghouan, 2003, pp. 283-289.

13. Á. GALmÉs DE FuENTES, El libro de las batallas. Narraciones épico-caballerescas, 2 vols., CLEAM, 2, Madrid,1975; v. además F. GuILlén Robles, op. cit., vol. III, pp. 199-275.

14. F. Bellino, «'Alī contro Geni, Demoni e Dragoni nella letteratura delle magāzī leggendarie», Quaderni di Studi Arabi, n.s. 1, 2006, pp. 155-170.

15. Sobre esta transmisión de al-Ṭalamankī véanse los estudios de E. LANDAU TASSERON, «New data on an old manuscript: An Andalusian version of the work entiled Futñh al-Shām», Al-Qanțara, XXI, 2000, pp. 361-380; S. MOURAD, «On Early Islamic Historiography: Abñ Ismācîl al-Azdī and his Futūḥ al-Shām», Journal of the American Oriental Society, 120/4, 2000, pp. 577-593.

16. M. Fierro, «El proceso contra Abū 'Umar al-Ṭalamankī a través de su vida y de su obra», Sharq al-Andalus, 9, 1993, pp. 93-127, p. 114. 
Lugo Acevedo -y otros autores que se han ocupado tanto del Kitāb al-anwār como del Libro de las luces- tienden a calificarlo como obra de inspiración sufí o de tendencias sufíes. Cabe sin duda esa posibilidad. Puedo añadir que las obras que circulaban en al-Andalus en cuyos títulos aparece el término anwār son tardías (se pueden documentar a partir del s. V / XI), muy escasas y casi todas ellas tienen que ver con composiciones relativas al profeta Muhammad. Es el caso de Anwār al-ātāar fì faḍl al-șalāt 'alà l-nabī l-mujtār de Aḥmad b. Ma'add Ibn al-Uqlīšì (478/1085-circa 550/1155) ${ }^{17}$, del Kitāb al-anwār wa-nafahāt al-azhār fì šamā'il alnabī al-mujtār de Muhammad b. ${ }^{\mathrm{c} A t \bar{q}}$ al-Lāridī (563/1167-637/1239) ${ }^{18}$ y de alAnwāar fì nasab āl al-nabī al-mujtār de Muhammad b. Aḥmad b. Muhammad b. Ahmad Ibn Ŷuzayy ${ }^{19}$, ya de época nazarí. Con anterioridad, se había introducido

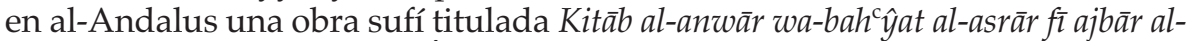
șălihīn del autor oriental Ibn Ŷahḍam (m. 414/1023), quien fue maestro de al-Ṭalamankī y cuya obra fue considerada sospechosa en su ortodoxia. Una obra sufí es también el Kitāb al-anwār de un autor llamado Abū 1-Qāsim ${ }^{\mathrm{C}} \mathrm{Abd}$ alRaḥmān b. Muḥammad b. 'Abd Allāh al-Bakrī al-Siqillī, que es citada por Ibn ${ }^{c}$ Abbād al-Rundī al-Šādilī $(733 / 1332-792 / 1390)^{20}$ y por el norteafricano al-Bādisī (vivo en el año 722/1322), autor de unas vidas de santos del Rīf (al-Maqșad al-šarîf fì $\left.\underline{\text { dikr }}{ }^{\mathrm{c}} u l a m \bar{a}^{\prime} a l-R \bar{\imath} f\right)^{21}$. En función de estos datos se puede deducir que en alAndalus el título anwar aparecía en biografías del Profeta en las que se ponían de relieve sus características excepcionales ( $\left.\check{s} a m \bar{a}^{\prime} i l\right)$, así como en algunas obras de inspiración sufí mal vistas por los agentes del islam normativo.

Las obras de los andalusíes Ibn al-Uqlisi, al-Laridi e Ibn Yuzayy -de las que sólo se ha editado la primera y se conoce un manuscrito de la tercera- pudieron contener materiales similares a los del Kitāb al-anwwār de al-Bakrī, entre otras razones porque de esta última obra se ha puesto de manifiesto que su contenido se puede rastrear en buena medida en otras obras consideradas ortodoxas ${ }^{22}$. Pero si es así, ¿a qué se debió la reprobación de al-Dahabī?

Para entender dicha reprobación, y sin rechazar la posible vertiente sufí del Kitāb al-anwār, hay que tener en cuenta otra dimensión de la obra de al-Bakrī,

17. Sobre este autor y su obra véase Biblioteca de al-Andalus, vol. 5, Enciclopedia de la Cultura andalusí, I., en J. Lirola Delgado y J.M. Puerta Vílchez (eds.), Almería, 2007, pp. 531-535, nº 1287 [Documentación].

18. Sobre este autor y su obra véase Biblioteca de al-Andalus, vol. 6, Enciclopedia de la Cultura andalusí, I., ed.de J. Lirola Delgado y J.M. Puerta Vílchez, Almería, 2009, pp. 465-467, nº 1504 [J.M. FórNEAS BESTEIRO - A. RODRÍGUEZ FIGUEROA]

19. Sobre este autor y su obra véase ibídem, pp. 180-195, n 1412 [F.N. VELÁZQUEZ BASANTA].

20. P. NwYIA, Un mystique prédicateur à la Qarawiyin de Fès: Ibn,Abbad de Ronda (1332-1390), Beirut, 1961, p. 196 (carta VIII sobre la penitencia). La cita del Kitāb al-anwwār de este otro al-Bakrī alSiqilli tiene que ver con la corrupción de la comunidad a lo largo de las siete generaciones que se han sucedido desde que falleció el Profeta Muhammad.

21. Ed. G.S. Colin en Archives marocaines, vol. 26, 1926.

22. Boaz SHOSHAN, op. cit., pp. 34-35. 
a saber, sus tendencias šííes, ya señaladas por otros autores ${ }^{23}$. El libro de al-Bakrī no se limita a insistir en aspectos milagrosos y fantásticos de la vida del Profeta que la biografía normativa tiende a minimizar o silenciar, a pesar de que -como ha demostrado Uri Rubin- con el paso del tiempo se advierte una tendencia clara a hacer del Profeta un hombre cada vez más excepcional y dotado de características cada vez más alejadas del común de los mortales ${ }^{24}$. Los especialistas en la literatura de los moriscos han registrado desde hace tiempo la presencia de estos elementos excepcionales en la caracterización del Profeta, tal y como puede comprobarse -por ejemplo- en algunos de los textos recogidos por Consuelo López Morillas en su monografía de $1994^{25}$. Pues bien, entre esos elementos, la idea de una luz que se transmite desde Adán hasta Muhammad -luz conocida como nūr muhammad $\bar{\imath}^{26}$ - es aceptada por los sunníes, pero con una cierta reticencia ${ }^{27}$ sobre todo en comparación a los š̃̌íies, en cuya cosmología e imamología desempeña un papel crucial. En efecto, para los šî́íes, esa luz -transmitida de padres a hijos, pero también de madres a hijos- no se acaba con el Profeta Muhammad, sino que continúa en la línea de sus descendientes, y al hacerlo contribuye a hacer de ellos seres especiales elegidos para el liderazgo carismático de la comunidad ${ }^{28}$. Y como las mujeres pueden ser vehículos en la transmisión de esa luz, el hecho de que los descendientes de ${ }^{\mathrm{c}} \mathrm{Alī}$ lo sean -en parte-también del Profeta -a través de su hija Fátima, una de las mujeres de ${ }^{\mathrm{c}} \mathrm{Al} \overline{\mathbf{i}}$ - garantiza que la nūr muhammadī se conserva tras la muerte de Muhammad en la línea de esos descendientes ${ }^{29}$. Lo que quiero subrayar con esto es que las reticencias hacia el Kitāb al-anwwār en al-Andalus debieron de venir por el lado de la amenaza potencial que el contenido de dicho libro representaba para la legitimidad sunní predominante en la Península Ibérica. El Kitāb al-

23. Ibídem, p. 38.

24. U. RuBIN, The eye of the beholder. The life of Muhammad as viewed by the early Muslims. A textual analysis, Princeton, N.J., 1995.

25. Textos aljamiados sobre la vida de Mahoma: el Profeta de los moriscos, edición y estudio de C. LópezMORILlAS, Madrid, 1994.

26. U. RuBIN, «Pre-existence and light. Aspects of the concept of Nūr Muhammad», Israel Oriental Studies, V, 1975, pp. 62-129.

27. El tratamiento sobrio y circunspecto de la luz del Profeta en la obra que el autor sunní 'Iyād de Ceuta (m. 544/1149) dedicó a las virtudes y a la veneración por el Profeta (al-šsifā $b i-t a^{c} r \bar{\imath} f$ huqūq al-Muștafā, 2 vols. en 1, Beirut: Dār al-kutub al-'ilmiyya, s.a., I, pp. 81-87, con todas las cadenas de transmisión, y p. 237) contrasta con el tratamiento en el Kitāb al-anwār / Libro de las luces. Creo que hay que plantearse hasta qué punto la obra de 'Iyād pudo ser compuesta para contrarrestar desde el punto de vista sunní no sólo el profetismo beréber, sino también obras como el Kitāb al-anwār.

28. U. RuBIN, «Prophets and progenitors in the early Shr̄a tradition», Jerusalem Studies in Arabic and Islam, 1, 1979, pp. 41-65.

29. Sobre la importancia de Fátima (el Mahdī será uno de sus descendientes: min abnā'/wuld Fātíma) véase M. FIERro, «On al-fāțimī and al-fāțimiyyūn», Jerusalem Studies in Arabic and Islam, 20, 1996, pp. 130-161. 
anwār -con su insistencia en la luz profética que se transmite también a través de las mujeres- puede ser usado como una poderosa arma de propaganda a favor del liderazgo carismático de la comunidad localizado en los descendientes directos del Profeta, aunque la obra no trate de forma directa este tema. Pero precisamente por las implicaciones que tiene, se trata de una obra que no podía sino ser rechazada y estigmatizada por los representantes del islam normativo peninsular, caracterizado por el malikismo y el anti-šǐísmo desde épocas muy tempranas y en especial durante el s. IV / X, a causa de la amenaza que el califato fatimí representó para la legitimidad omeya ${ }^{30}$.

Cabe pues la posibilidad de que Kitāb al-anwā̄r fuese elaborado en círculos ššcíes ${ }^{31}$, y tal vez ismāî̀líes. Lo que sigue es una propuesta para leer el Kitāb al-anwār en un marco šíí:

- Al tratar la genealogía más antigua del Profeta en el Kitāb al-anwār se pasa directamente de Adán y los descendientes directos de éste a los antepasados más cercanos de Muhammad, obviándose los eslabones intermedios de la genealogía árabe bien asentados en la tradición biográfica sunní del Profeta. Pero para los šĩćes, la genealogía árabe no es la única que importa, pues casi tiene más importancia la que conecta al Profeta en tanto que tal con los Mensajeros de Dios que le precedieron (que no fueron árabes) y a través de los cuales recibió la $n \bar{u} r$ Allāh. La omisión de los eslabones 'intermedios' en el Kitāb al-anwār podría ser intencionada para no entrar en una cuestión que servía para identificar a los šĩíes y facilitar por ello su circulación entre un público sunní, pero de manera que se despertase el interés sobre quiénes eran exactamente esos eslabones que faltaban, posibilitando así que al curioso se le pudiese dar de una manera menos pública la información omitida e ir introduciéndole en doctrinas más esotéricas.

- Los ismācīlíes desarrollaron un sofisticado aparato de 'agitación y propaganda' que se movía en distintos niveles y que se adaptaba al tipo de audiencia al que se dirigía ${ }^{32}$. El Kitāb al-anwār responde perfectamente a lo que se esperaría de una obra ismā̄îli dirigida a una audiencia 'popular' en la que se

30. Puede verse al respecto M. FIERro, «Espacio sunní y espacio ššcíi», en El esplendor de los omeyas cordobeses. La civilización musulmana de Europa Occidental. Exposición en Madīnat al-Zahrā', 3 de mayo a 30 de septiembre de 2001, Granada, 2001, 168-177 y «Madīnat al-zahrā', el Paraíso y los fatimíes», Al-Qanțara, XXV, 2004, pp. 299-327.

31. Dado que la solución š̌̃í al problema del liderazgo de la comunidad debió ser -de acuerdo con lo formulado por P. CRONE y M. HINDS, God's caliph. Religious authority in the first century of Islam, Cambridge, 1986- la solución original frente a la sunní que terminó imponiéndose, las implicaciones de la propuesta 'hereditaria' de la autoridad carismática recogida en el Kitāb alanwār se remonta a los primeros siglos, con independencia de las elaboraciones posteriores a las que dicha doctrina fue sometida.

32. Una clara demostración de esta adaptabilidad a distintos tipos de público -por ejemplo, el compuesto por mujeres- se encuentra en una extraordinaria obra que recoge las memorias de uno de los 'misioneros' ismā̄īlíes: The Advent of the Fatimids. A contemporary Shic $i$ Witness. An Edition and English Translation of Ibn al-Haytham,s Kitab al-Munāzarāt de W. MADELUNG y P.E. WALKER, London / New York, 2000. 
pone el énfasis en aquellos materiales susceptibles de atraer el interés del común del pueblo, pero entreabriendo la posibilidad de ir introduciendo materiales más complejos si alguien entre el público quería saber más. Precisamente por la habilidad de sus misioneros a la hora de atraer a las masas, los califas omeyas andalusíes restringieron al máximo en su territorio la actividad de los predicadores o narradores de historias populares. Intentaban poner así freno a la penetración de los propagandistas ismāçilíes, causantes de la rebelión de Ibn al-Qitț en las Marcas Media e Inferior, de haber logrado atraer a Ibn Hafșūn a la causa fatimí durante un tiempo y de haber instigado la actividad de un agitador en Córdoba durante el califato de al-Hakam II ${ }^{33}$.

- Lo que se sabe de la circulación del Kitāb al-anwār en el Egipto mameluco lo vincula a la celebración de la festividad del nacimiento del Profeta o mawlid $^{34}$. Pues bien, se trata de una festividad que fue innovada por los fatimíes $^{35}$, es decir, por la dinastía que logró establecer un califato ismā'îlí en el Norte de África en el año 296/909 y que trasladó su capitalidad a Egipto tras la conquista de este territorio en el año 361/972. Los fatimíes apoyaron dicha celebración -junto con los mawlids de ${ }^{\mathrm{c}} \mathrm{Alī}$, Fāțima, al-Husayn, al-Hasan y el califa reinante ${ }^{36}$ - porque servía para reforzar entre sus súbditos la idea de que la legitimidad fatimí derivaba precisamente de su genealogía, que los hacía herederos directos ('de sangre') del Enviado de Dios. Pues bien, la lectura de un libro como el Kitāb al-anwār durante esa festividad no podía sino contribuir a fortalecer aún más el mensaje que se quería transmitir. La penetración del mawlid del Profeta en contextos sunníes, que tuvo lugar sobre todo a partir del s. VII / XIII, pudo contribuir a la difusión del Kitāb al-anwār fuera de los círculos ismāçílíes, en un ambiente en el que la atracción antaño ejercida por las doctrinas ismācilíes iba dando mayor protagonismo al sufismo ${ }^{37}$.

Sin quitarle lo que tiene de reconstrucción hipotética, creo que lo expuesto ofrece un marco de interpretación plausible sobre el porqué de la reprobación del Kitāb al-anwār por parte de los ulemas sunníes y sobre el porqué del silencio de las fuentes andalusíes sobre su circulación en la Península Ibérica ${ }^{38}$.

33. M. FIERRO, «La política religiosa de 'Abd al-Rahmmān III», Al-Qanțara, XXV, 2004, pp. 119-156.

34. Boaz SHoshan, op. cit., p. 37; M.L. LUGo AceVEDo (ed.), op. cit., p. 27.

35. N.J.G. KAPTEIN, Muhammad's birthday festival: early history in the central Muslim lands and development in the Muslim west until the 10th/16th century, Leiden, 1993, pp. 7-30.

36. P. SANDERS, Ritual, politics, and the city in fatimid Cairo, New York, 1994, pp. 35-36, 115.

37. La atribución del Kitāb al-anwār a un autor claramente ficticio al que se le da la nisba de al-Bașrī pudo ser una forma de ocultar su carácter sĩ̄í: Basora no está asociada en el imaginario musulmán al š̃̃ísmo como sí lo está Kufa. Por otro lado, Basora sí está asociada en dicho imaginario al mundo del ascetismo y del sufismo, así como de los predicadores populares: véase al respecto Ch. Pellat, Le milieu bașrien et la formation de Ğāhiz, París, 1953.

38. La circulación del Kitāb al-anwār en la primera mitad del s. VI/XII en al-Andalus que desembocó en su traducción latina parece indicar que debió de tener un carácter hasta cierto punto 'público'. Ello pudo ser debido, por un lado, al hecho de que en época almorávide la alta 
El silencio de esas fuentes sobre obras como los Futūh al-Š $\bar{a} m$ legendarios y el Kitāb al-anwār no es el único que se puede aducir para subrayar la parcialidad de las fuentes con las que solemos reconstruir la vida intelectual andalusí. Otro caso es el relativo a los libros de magia que circulaban entre los moriscos. Como ya apuntó Ana Labarta, especialmente en su estudio del Libro de dichos maravillosos:

“a menudo se habla, con cierta ligereza, de la afición morisca por las ciencias ocultas, la magia y la hechicería; se ha llegado a afirmar incluso que 'no había morisco, por piadoso que fuera, que dejara de tener libros llenos de recetas mágicas', cosa que es absolutamente falsa. Se pretende justificar luego este tópico diciendo que los moriscos habían perdido la gran tradición científica del Islam y que la concepción fatalista de la existencia inherente a su religión favoreció el renacer de tales ciencias. Resulta un expediente muy cómodo relacionar superstición y declive cultural para justificar la presencia de la hechicería y la magia entre los moriscos, privados -se enfatiza- de una élite cultural que les guiase. Creo haber demostrado -sigue diciendo Ana Labarta-, sin embargo, que los moriscos no eran cuantitativamente más supersticiosos que sus contemporáneos cristianos viejos, sino todo lo contrario. Habría que demostrar -y no se ha hechoque los musulmanes españoles de los últimos siglos eran más aficionados a las ciencias ocultas que los que les precedieron" ${ }^{\prime 39}$.

De hecho, el contenido del manuscrito estudiado por Ana Labarta procede de fuentes antiguas que se pueden rastrear en siglos anteriores, es decir, no es una obra nacida -como casi ninguna de los moriscos- en el siglo XVI. Pero nuevamente, si nos dejamos llevar por los cauces por los que quiere llevarnos la 'historia oficial' de la vida intelectual andalusí, habríamos de concluir que las obras de magia no circularon apenas en al-Andalus, pues son prácticamente invisibles en las fuentes andalusíes.

Para terminar, no son los mudéjares y moriscos los únicos que nos ayudan a entender mejor la actividad intelectual andalusí en toda su complejidad y riqueza. También la actividad y producción intelectuales de los judíos de al-Andalus nos permiten atisbar corrientes hasta cierto punto subterráneas entre los musulmanes, sobre todo en disciplinas tales como la filosofía o el sufismo. En conclusión, la historia intelectual de al-Andalus no puede ser escrita sin tener en cuenta a sus 'minorías', ya sean estas no musulmanas en territorio islámico o musulmanas en territorio cristiano.

cultura pasa a un segundo plano (piénsese en el éxito de los zéjeles de Ibn Quzmān) y, por otro lado, a que los almorávides, especialmente hacia el final de su reinado, intentaron dotarse de una autoridad carismática próxima a la $\mathrm{s}_{\mathbf{1}}^{\mathrm{C}} \mathrm{i}$, camino éste que será el adoptado desde el primer momento por los almohades (M. FIERRO, «Entre el Magreb y al-Andalus: la autoridad política y religiosa en época almorávide», en F. SABATÉ (ed.), Balaguer, 1105. Cruïlla de civilitzacions. Reunió Científica. X Curs d'Estiu Comtat d'Urgell celebrat a Balaguer els dies 13, 14 i 15 de juliol de 2005 sota la direcció de Flocel Sabaté i Maribel Pedrol, 2007, pp. 99-120).

39. Libro de dichos maravillosos (Misceláneo morisco de magia y adivinación), introducción, interpretación, glosario e índices por A. LABARTA, Madrid, 1993, p. 0.8. 


\section{RESUMEN}

El Libro de las luces es una obra musulmana cuya circulación en la Península Ibérica está atestiguada entre mudéjares y moriscos, si bien hay evidencias que muestran que era conocida con anterioridad en su original árabe, el Kitāb al-anwār. El silencio de los diccionarios bio-bibliográficos andalusíes sobre la transmisión y lectura de esta obra en al-Andalus plantea cuestiones que tienen que ver con el control del conocimiento religioso islámico y con el establecimiento de ciertos límites en lo que se consideraba aceptable o normativo, sobre todo en relación a las concepciones de la autoridad política y religiosa. El análisis de este caso concreto muestra la necesidad de tener en cuenta a los grupos 'minoritarios' a la hora de escribir la historia intelectual de al-Andalus. ligioso.

Palabras clave: mudéjares, moriscos, Libro de las Luces, conocimiento re-

\section{ABSTRACT}

The Libro de las luces is a Muslim work circulating in the Iberian Peninsula among Mudéjars and Moriscos, although there is evidence indicating that it was known before in its Arabic original, the Kitāb al-anwwār. The silence of Andalusi bio-bibliographical dictionaries on the transmission of this work in al-Andalus draws attention to issues having to do with the control of Islamic religious knowledge and with the establishment of limits concerning what was deemed to be acceptable or normative, especially in relationship to conceptions of political and religious authority. The analysis of this specific case illuminates the need to take into account 'minority' groups when writing the intellectual history of al-Andalus.

Key words: Mudejars, Moriscos, Kitāb al-anwārr, religious knowledge. 